Review

\title{
Measuring and monitoring skeletal muscle mass and dysfunc- tion after stroke
}

\author{
Nobuto Nakanishi ${ }^{1, *}$, Kazuki Okura ${ }^{2}$, Masatsugu Okamura ${ }^{3}$, Keishi Nawata ${ }^{4}$, Ayato Shinohara ${ }^{5}$, Kohei Tanaka ${ }^{6}$, \\ Sho Katayama ${ }^{7}$
}

1 Emergency and Critical Care Medicine, Tokushima University Hospital, 2-50-1 Kuramoto, Tokushima 7708503, Japan; nobuto_nakanishi@yahoo.co.jp (N.N.)

2 Department of Rehabilitation, Akita University Hospital, 44-2 Hasunuma, Aza, Hiroomote, Akita, 010-8543, Japan; azu.ajaj@gmail.com (K.O.)

3 Department of Rehabilitation, Yokohama City University Hospital, 3-9 Fukuura, Kanazawa, Yokohama, Kanagawa 236-0004, Japan; okamura@yokohama-cu.ac.jp (M.O.)

4 Department of Rehabilitation, University Hospital of Occupational and Environmental Health, 1-1 Iseigaoka, Yahata-nishi, Kitakyushu, Fukuoka 807-8556, Japan; nawakei.1221@gmail.com (K.N.)

5 Department of Rehabilitation, Fujita Health University Hospital, 1-98 Dengakugakubo, Kutsukake, Toyoake, Aichi 470-1192, Japan; ayato@fujita-hu.ac.jp (A.S.)

6 Department of Rehabilitation Medicine, Osaka Police Hospital, 10-31 Kitayama, Tennouji, Osaka 543-0035, Japan; kohei.t68@gmail.com (K.T.)

7 Department of Rehabilitation Medicine, Okayama University Hospital, 2-5-1 shikata, Kitaku, Okayama 7008558, Japan; rhsy.0112@gmail.com (S.K.)

* Correspondence: nobuto_nakanishi@yahoo.co.jp; Tel. +81-88-631-7151

\begin{abstract}
Muscle mass at admission is important to survive stroke, and stroke-induced sarcopenia is a serious problem because of its poor prognosis. Muscle mass measurement and monitoring are essential for appropriate re-habilitation and nutrition management. Several methods are used to assess skeletal muscle mass in stroke, such as computed tomography (CT), ultrasonography, bioelectrical impedance analysis, dual-energy X-ray absorptiometry, biomarkers, and anthropometrics. In stroke, a head CT is used to estimate muscle mass by measuring the temporal muscle. However, it is mostly retrospectively conducted due to radiation exposure. After stroke, limb muscle atrophy and diaphragm dysfunction are observed using ultrasound. However, ultrasound requires an understanding of the methods and skill. A bioelectrical impedance analysis can be used to assess muscle mass in patients after a stroke unless they have dynamic fluid changes. Dual-energy X-ray absorptiometry is used for follow-up after hospital discharge. Urinary titin N-fragment and serum Cterminal agrin fragment reflect muscle atrophy after stroke. Anthropometrics may be useful with limited resources. We summarized the features of each measurement and proved the recent evidence to properly measure and monitor skeletal muscle mass after stroke.
\end{abstract}

Keywords: stroke; sarcopenia; computed tomography; ultrasound; bioelectrical impedance analysis; muscle; temporal muscle; rectus femoris muscle; diaphragm; calf circumference

\section{Introduction}

Stroke is the second leading cause of death worldwide [1]. Annually, 17 million people suffer from stroke and 6 million people die. In this decade, the mortality ratio decreased due to advancements in stroke treatment [2]. However, many patients suffer from the prolonged physical dysfunctions after hospital discharge. A previous study reported that only $29 \%$ return to work during the first year after stroke onset [3].

To survive a stroke, muscle mass plays an important role. Since most strokes occur in patients over 65 years old, sarcopenia is prevalent at the stroke onset [4]. At the stroke onset, low muscularity is associated with poor clinical outcomes [5]. Furthermore, after the stroke onset, muscle atrophy, called "stroke-induced sarcopenia," is associated with 
worse clinical outcomes, such as mortality and physical dysfunction [6]. Stroke-induced sarcopenia is observed in $42 \%$ of stroke survivors [7], and muscle loss is observed in the affected and unaffected limbs [8].

Measuring and monitoring muscle mass to provide proper nutrition and rehabilitation to patients who are at the greatest risk of muscle atrophy are important. Several methods are used to assess skeletal muscle mass after stroke, including computed tomography (CT), ultrasonography, bioelectrical impedance analysis (BIA), dual-energy X-ray absorptiometry (DEXA), biomarkers, and anthropometrics. We summarized each measurement method and their applications in patients with stroke.

\section{Computed tomography (CT)}

\subsection{Methodology}

CT can accurately measure muscle mass because it can distinguish muscle and other tissues. Thus, CT is often used as the gold standard of muscle mass estimation. In a study using a cadaver, the measurement of lower limb muscle mass using CT was consistent with the measurement of lower limb muscle mass and the actual size of the cadaver using magnetic resonance imaging (MRI) [9]. However, due to radiation exposure and transfer of patients to the examination room, muscle mass assessment using CT is often retrospectively conducted in patients with stroke.

Several software can be used in measuring muscle mass, and no significant difference in the measurement was observed between software $(r=0.979-1.000 ; p<0.001)$ [10]. ImageJ (National Institutes of Health, Maryland, USA) is a frequently used free software [11]. This software needs manual tracing to measure muscle mass in a 2-dimensional plane. The problem of manual tracing is the difficulty to distinguish fat tissues. One method for discriminating muscle from fat is using CT-derived skeletal muscle density, in which the muscle has the ranges from -29 to 150 Hounsfield unit.

Muscle mass measurement is conducted at the middle level of the third lumbar vertebra because the measurement at this landmark correlated with lean body mass on DEXA $(\mathrm{r}=0.86-0.94 ; \mathrm{p}<0.001)$ [12]. However, in stroke, taking CT images of the trunk is unusual. Thus, head CT is used to evaluate muscle mass in patients with stroke. Several studies have used the temporal or paravertebral muscle area at cervical vertebra levels (Figure 1). Temporal muscle thickness and area can be measured at the orbital roof level [13-15], 5 $\mathrm{mm}$ above the level [16,17], or the thickest portion of the temporal muscle [18]. Thickness is measured at the maximum point in the plane, and area is measured manually [16] or automatically [18]. Sylvian fissure is used to confirm anteroposterior orientation. There is a correlation between temporal muscle thickness and area $(r=0.38-0.40)$ [18]. Temporal muscle thickness was correlated with whole muscle mass at the third lumbar vertebra in patients with brain metastases $(\mathrm{r}=0.733$; $\mathrm{p}<0.001)[13]$ and the psoas muscle area $(\mathrm{r}=0.57$; $\mathrm{p}<0.001)$ in patients with trauma [18]. Furthermore, temporal muscle thickness is correlated with hand grip strength $(\mathrm{r}=0.649-746 ; \mathrm{p}<0.001)$ [15]. Alternatively, the paravertebral and sternocleidomastoid muscle cross-sectional areas at the third cervical vertebra were correlated with whole muscle mass at third lumbar vertebra $(r=0.785)$ in patients with head and neck cancer [19]. These muscle mass measurements are conducted bilaterally considering the affected or unaffected side. In addition, a qualitative assessment of muscle mass is conducted using CT-derived skeletal muscle density and lower density means fatty degeneration [20]. 


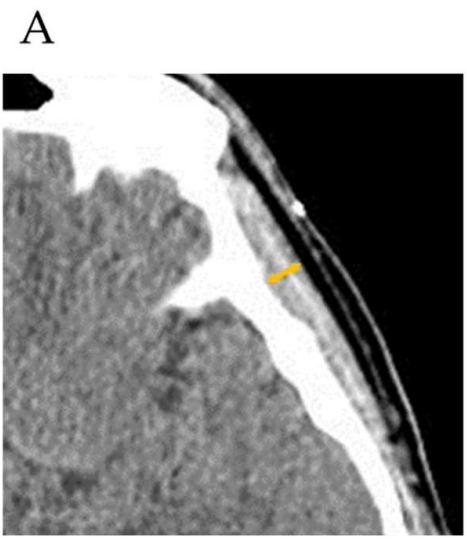

B

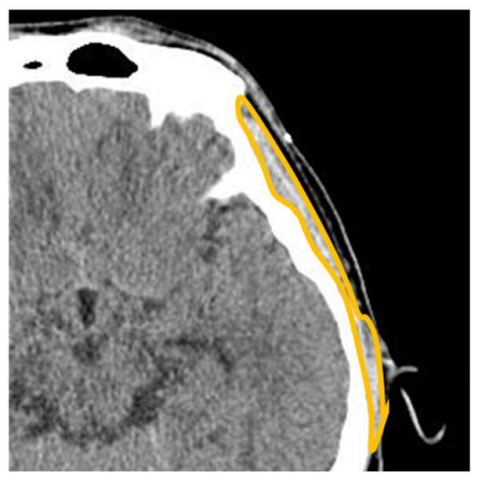

Figure 1. An image of muscle mass evaluation in brain computed tomography. A. Temporal muscle thickness. B. Temporal muscle cross-sectional area.

\subsection{Applications in stroke}

In patients with stroke, temporal muscle thickness at admission was independently associated with sarcopenia, assessed using a questionnaire $(\beta=-0.138 ; \mathrm{p}=0.02)$ [14]. In another study, temporal muscle thickness was associated with a poor neurological prognosis at three months, defined as Glasgow Outcome Scale scores of 1-3, in neurocritically ill patients, including those with stroke (adjusted odds ratio (OR), 1.27; 95\% confidence interval (CI), 1.028-1.576) [21]. The temporal muscle area was evaluated in patients with subarachnoid hemorrhage, and on admission, it was independently associated with modified Rankin Scale scores six months after aneurysm treatment, and the cutoff value of temporal muscle area was $<200 \mathrm{~mm}^{2}$ [16]. Because temporal muscle mass affects physical functions at hospital discharge in patients after aneurysm treatment, it can be a good indication for surgical intervention in aneurysm treatment [17].

One study has investigated the paravertebral muscle cross-sectional area at the transverse process level of the first cervical vertebra. The muscle atrophy in the first cervical vertebra was associated with a poor neurological outcome, defined as Glasgow Outcome Scale scores of 1-3 at three months (adjusted OR, 1.36; 95\% CI, 1.054-1.761) [21]. The validation of the paravertebral muscle mass at the first cervical vertebra needs further study. Another study has assessed the paravertebral muscle area at the third lumbar vertebral, and they found that a decreased cross-sectional area was associated with functional impairments in patients with stroke [22].

\section{Limb ultrasonography}

\subsection{Methodology}

Ultrasound can distinguish muscle from other tissues, but it requires skill and experience to properly measure the muscle mass. Ultrasound is available at the bedside. Thus, it is a promising tool for monitoring muscle mass after stroke.

After stroke, muscle mass assessments using ultrasound have been conducted in the rectus femoris, tibialis anterior [23], medial gastrocnemius muscle [24], and foot [25] and hand muscles [26], among others. Among them, the rectus femoris muscle is a well-established landmark of muscle mass assessment using ultrasound. There are several measurement points in rectus femoris muscle measurements using ultrasound (Figure 2): (1) at the midway between the anterior superior iliac spine and proximal end of the patella [27, 28], (2) two-thirds the distance from the anterior superior iliac spine to the proximal end of the patella, and (3) at 10-15 cm above the upper border of patella [29]. These measurement points have good correlations. In a study, the correlation coefficients were 0.87 and 0.88 at the midway and $15 \mathrm{~cm}$ above the upper border of patella [30], whereas in another study, the correlation coefficients were $0.74-0.76$ and $0.81-0.83$ at the midway and two- 
thirds points [31]. Considering probes, linear probes are used for measurements. However, linear probes with a short width cannot capture the rectus femoris muscle in one image and two images need to be combined to measure the cross-sectional area using the landmark of the central aponeurosis [32, 33]. In a study, a convex probe was validated, but it is not usually used in muscle mass assessment due to insufficient visualization [32]. Fluid accumulates in subcutaneous tissue, and muscle mass measurement using ultrasound did not correlate with fluid change [27]. Because compression strength affects the measurements [34], generous amounts of contact gel need to be used to avoid compression of the muscles by the probe. The transducer was placed perpendicular to the long axis of the limbs because the angle of the probe affects the measurements [35]. A mark needs to be drawn on the skin for longitudinal measurements in the same location. Measurements should be conducted in a flat position with the legs passively extended because the measurements in the rectus femoris cross-sectional area increases at the bed angles of $0^{\circ}\left(3.33 \mathrm{~cm}^{2}\right), 20^{\circ}\left(3.47 \mathrm{~cm}^{2}\right), 30^{\circ}\left(3.58 \mathrm{~cm}^{2}\right)$, and $60^{\circ}\left(3.70 \mathrm{~cm}^{2}\right)$ [29]. Several studies in critical illness have reported that the cross-sectional muscle area correlates with muscle function, but thickness does not correlate with muscle function [36, 37]. Thus, the measurement of the cross-sectional area may be desirable after stroke, although most studies on stroke have measured muscle thickness. Muscle thickness often includes not only the rectus femoris but also the vastus intermedius muscle from the superficial fascia of the rectus femoris muscle to the femur. Intraobserver and interobserver correlation coefficients were 0.740.99 and 0.76-0.99, respectively, for thickness and 0.98-0.99 and 0.98-0.99, respectively, for cross-sectional area [27, 30, 31, 38, 39]. In a qualitative analysis, an increased echointensity represents muscle mass loss and fibrous muscle changes [40]. In critical illness, an increased echo-intensity is correlated with rectus femoris muscle atrophy and impaired physical functions [41].

A

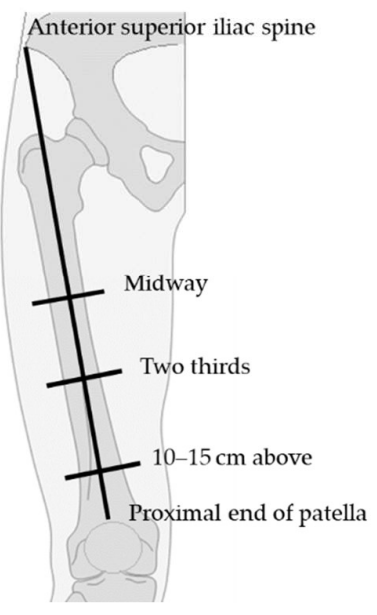

B

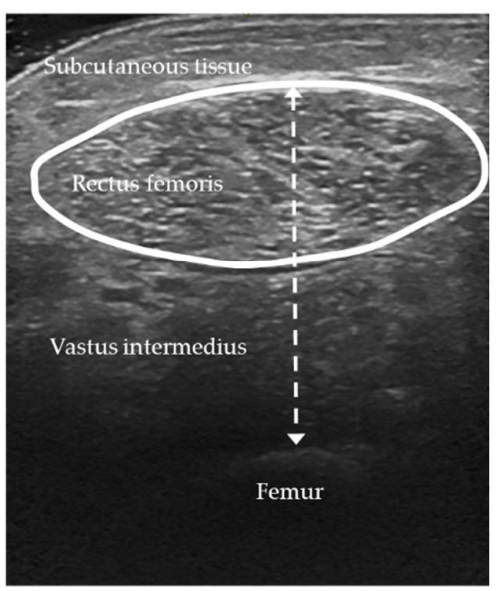

Figure 2. Rectus femoris muscle evaluation using ultrasound. A. Measurement position at the femur. B. An ultrasound image of a rectus femoris cross-sectional area and thickness from the superficial fascia of the rectus femoris muscle to the femur.

\subsection{Applications in stroke}

Ultrasound measurements at the anterior thigh are reliable after stroke [38]. After stroke, robust muscle changes occur in the quadriceps femoris muscles compared with other muscles [42]. In a study, ultrasound assessments showed that quadriceps muscle thickness decreased by $20.8 \%$ in the affected limb and $15.3 \%$ in the unaffected limb within two weeks of the acute phase [28]. In patients with acute aneurysmal subarachnoid hemorrhage, quadriceps muscle thickness decreased by $11.0 \%$ in 2 weeks, and the extent of atrophy was correlated with the Hunt and Hess grade $(r=-0.72 ; p=0.001)$ and the modified Rankin Scale score at 90 days $(r=-0.78 ; p=0.0002)$ [43]. In a 3-year follow-up of 20 stroke survivors, quadriceps muscle thickness still decreased by $10.3 \%$ in the affected limb 
and $17.0 \%$ in the unaffected limb from the baseline [44]. The echo-intensity of the muscles in these patients increased by $20.0 \%$ in the affected limb and $24.9 \%$ in the unaffected limbs. In addition to echo-intensity, muscle stiffness, measured using elastography, increases in qualitative muscle changes after stroke [45]. Ultrasound measurements of rectus femoris muscle cross-sectional area can be used to assess the effects of an interventional study. Studies have used the rectus femoris cross-sectional area to assess the effect of strength training [46] or anabolic steroid treatment [47] and confirmed their positive effects.

\section{Ultrasound in diaphragm}

\subsection{Methodology}

Diaphragm muscle mass can be measured using ultrasound. Ultrasound evaluation of diaphragm thickness is reliable because it is correlated with cadaveric diaphragm thickness $(r=0.93)$ [48]. Diaphragm thickness is measured using linear probes with B mode (desirably high resolution $\geq 10 \mathrm{MHz}$ ). The patient position should be the spine position with the bed reclined at a $30^{\circ}$ angle. The probe needs to be placed perpendicular to the right chest wall at the eighth to tenth intercostal spaces in the anteroaxillary and midaxillary lines. This position helps identify the costophrenic sinus. The probe is moved $0.5-2.0$ $\mathrm{cm}$ caudally below the costophrenic sinus to measure the diaphragm in parallel without rib shadow. This position is called the "zone of apposition." In the zone of apposition, the diaphragm has a three-layered structure. Although the right diaphragm is measurable in $95 \%$ of attempts, the left diaphragm is often difficult to be clearly observed through the spleen window partly due to the interference of the stomach [49]. Unless patients have hemilateral diaphragm paresis, right and left diaphragm functions are not different [49]. The hypoechogenic muscular layer of the diaphragm is bordered by the echogenic layers of the peritoneum and diaphragmatic pleura. Diaphragm thickness at end expiration is measured three times with the median value used for the evaluation. In healthy volunteers, the average of diaphragm thickness at end expiration was $0.19 \pm 0.04 \mathrm{~cm}(95 \% \mathrm{CI}$, $0.17-0.20 \mathrm{~cm})$ for men and $0.14 \pm 0.03 \mathrm{~cm}(95 \% \mathrm{CI}, 0.13-0.15 \mathrm{~cm})$ for women [50]. Intraobserver and interobserver correlation coefficients were $0.88-0.98$ and $0.97-0.99$, respectively, in thickness measurements [51].

Diaphragm functions are assessed using two methods (Figure 3). Using a linear probe, the thickening fraction can be calculated as follows: [thickness at inspiration - thickness at expiration]/[thickness at expiration] $\times 100$. The average thickening fraction in normally breathing healthy volunteers was $15 \%-30 \%$ [52]. The thickening fraction depends on the patients' breathing [53]. The thickening fraction is used to assess diaphragm functions. Another method for assessing diaphragm functions is measuring diaphragm excursion. Diaphragm excursion is evaluated at the midclavicular line in the subcostal area using a convex or sector probe $(2-5 \mathrm{~Hz})$ where the liver is used as sound windows for the right diaphragm. In the $\mathrm{M}$ mode, diaphragm excursion is measured as the distance from the lower to the upper borders of diaphragm movement. The normal range is $>1 \mathrm{~cm}$, and diaphragm excursion values $<1 \mathrm{~cm}$ are often used to denote diaphragm dysfunction. In addition, diaphragm excursion is used to calculate diaphragm contraction velocity-diaphragm excursion divided by the inspiratory time-and the excursion-time index - the product of diaphragm excursion and inspiratory time. These parameters using diaphragm excursion reflect the expansion of the rib cage. Thus, it is influenced by other rib cage respiratory muscles. Intraobserver and interobserver correlation coefficients were 0.950.99 and $0.58-0.99$, respectively, in excursion measurements [51]. Diaphragm dysfunction can be clearly distinguished when patients are asked to force-fully breathe instead of normal breathing [54]. 
A

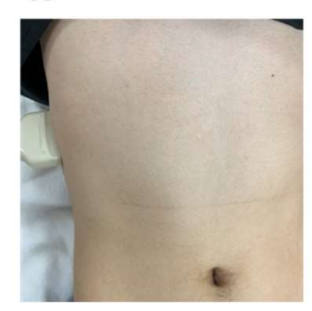

$\mathrm{B}$

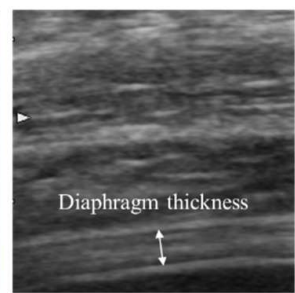

$\mathrm{C}$

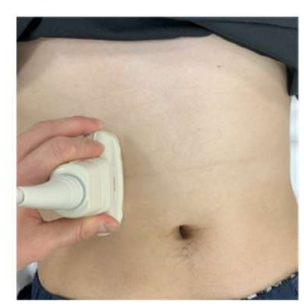

$\mathrm{D}$

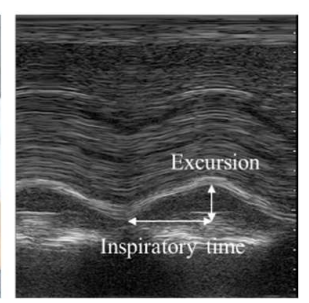

Figure 3. Diaphragm muscle assessment using ultrasound. A. Measurement to assess diaphragm thickness. B. An ultrasound image of diaphragm thickness in the B mode of a linear probe. C. Measurement to assess diaphragm excursion. D. An ultrasound image of diaphragm excursion in the $\mathrm{M}$ mode of a convex probe.

\subsection{Applications in stroke}

Diaphragm thickness is thinner on the affected side than that on the unaffected side at end expiration [55], and diaphragm dysfunction was observed in $51.7 \%$ of affected limbs and $1.7 \%$ of unaffected limbs [54]. Diaphragm dysfunction was not only observed in patients with hemiparesis but also observed in $24 \%$ of patients without hemiparesis [56]. In the paresis side, the diaphragm response was abolished or markedly delayed on diaphragm electromyogram [57]. Decreased diaphragm excursion causes silent aspiration after stroke [58]. Since rehabilitation interventions are effective for respiratory muscle weakness after stroke, assessing the diaphragm functions is important [59]. Although the left hemidiaphragm is not routinely assessed for diaphragm function, examining bilateral hemidiaphragm functions after stroke is better. Especially, diaphragm dysfunction needs to be evaluated in patients with middle cerebral artery occlusion because the occurrence rate of diaphragm dysfunction was $62.5 \%$ among them [54].

\section{Bioelectrical impedance analysis (BIA)}

\subsection{Methodology}

BIA indirectly evaluates body composition from the impedance caused by electrical currents (Figure 4). Multifrequency BIAs using different electrical currents are more accurate than single-frequency BIAs because multifrequency BIAs can distinguish intracellular and extracellular water. Muscle mass is assessed using skeletal muscle mass or lean body mass, which is divided by the height square as skeletal or lean body mass index, respectively. In patients with fluid overload, muscle mass measurement using BIA needs careful interpretation. Kim et al. have reported that skeletal muscle mass measured using BIA was correlated with CT $(\mathrm{p}<0.001)$, but BIA overestimated muscle mass (mean difference, $3.35 \mathrm{~kg}$ ) particularly in an edematous patient [60]. Alternatively, Nakanishi et al. have reported that muscle mass monitoring using BIA differed from ultrasound measurements and BIA measurement was correlated with fluid balance $(r=0.37-0.51 ; p<0.01)$ [27]. Unlike critically ill patients, patients with stroke are not often edematous. Thus, BIA is often used after stroke unless patients are under dynamic fluid changes, such as those with raptured subarachnoid hemorrhage.

BIA does not require a high degree of technical skills. It should be measured with the patients on a flat position because postural changes affect the measurements. Indeed, Kushner et al. have reported that a postural change from standing to lying immediately increased impedance by 3\% [61]. The upper and lower limbs should be detached from the trunk. Numerous products are available from different companies including Inbody (Seoul, South Korea), Tanita (Tokyo, Japan) [62, 63], and Bioscan (Malton International, Essex, England). Inbody is often used after stroke [5]. Edema can be distinguished using extracellular water (ECW) divided by total body water (TBW). The normal range of $\mathrm{ECW} / \mathrm{TBW}$ is $0.36-0.39$. ECW/TBW $\geq 0.40$ indicates an edematous state. Measurements using BIAs are conducted on the entire body or lateral side of the body (segmental) 
without differences in results [64]. In segmental measurements, no difference in the results was observed between affected and unaffected limb measurements after stroke [65]. The algorithm for calculating muscle mass differs among devices, and the measurement results are not comparable between different devices [66].

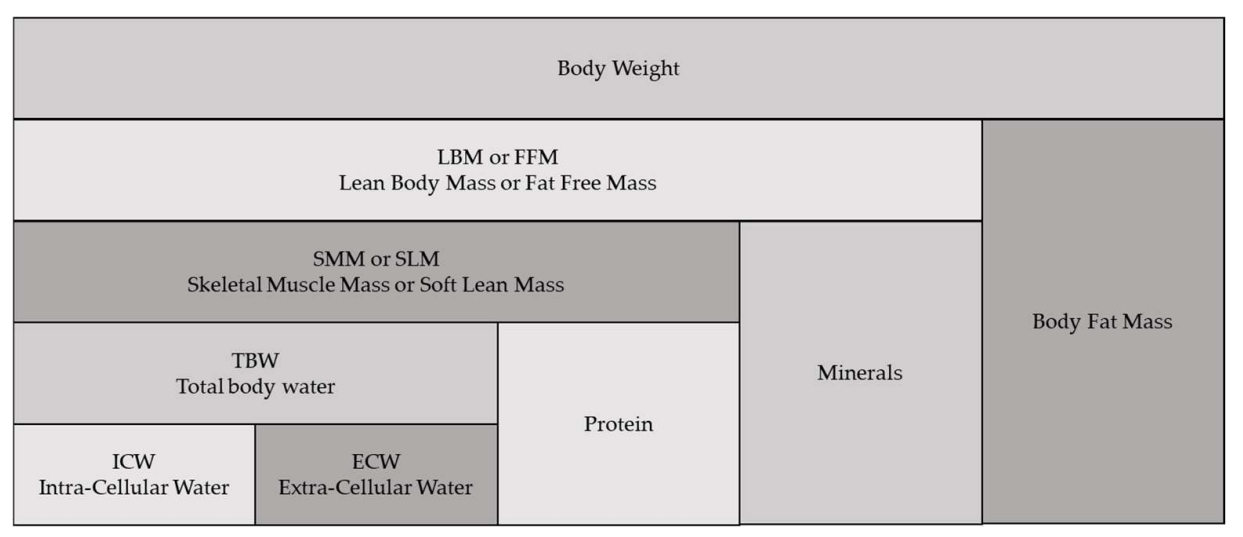

Figure 4. Body composition measured using bioelectrical impedance analysis.

\subsection{Applications in stroke}

In BIA, sarcopenia is defined as $<7.0 \mathrm{~kg} / \mathrm{m}^{2}$ in men and $<5.7 \mathrm{~kg} / \mathrm{m}^{2}$ in women according to the Asian Working Group for Sarcopenia [67]. Abe et al. have used BIA to evaluate sarcopenia in 107 patients after acute ischemic stroke [5]. They found that sarcopenia in the definition was independently associated with an impaired walking function at discharge (OR, 4.02; 95\% CI, 1.38-11.7; $\mathrm{p}=0.001$ ). Likewise, Ohyama et al. have shown that sarcopenia in the definition was associated with poor outcomes with modified Rankin Scale scores of 3-6 (OR, 2.58; 95\% CI, 1.07-6.24; $\mathrm{p}<0.05)$ and prolonged hospital stay ( $\mathrm{p}<$ 0.01 ) in 164 patients with acute ischemic stroke [68]. In BIA, phase angle is an important parameter, which is composed of tissue resistance and reactance, and represents muscle cellular integrity. Irisawa et al. have reported that a high phase angle is associated with a motor score of the Functional Independence Measure at four weeks (OR, 3.32) in patients with stroke [69].

Lean body mass gradually decreases in both the affected and unaffected limbs after stroke [70]. At the time of rehabilitation, stroke-induced sarcopenia was observed in 53.5\% of patients [71] and sarcopenic obesity was observed in $28 \%$ of patients [72]. Even with rehabilitation, muscle mass decreased by approximately $65 \%$ at hospital discharge and increased by approximately 30\% 12 weeks after hospital discharge without returning to the admission level [62]. Nagano et al. have investigated changes in skeletal muscle index in 272 patients with stroke and found that the changes in skeletal muscle index were significantly associated with a motor score $(\beta=0.175 ; \mathrm{p}=0.003)$ and motor gain score $(\beta=$ 0.247, $\mathrm{p}=0.003$ ) of the Functional Independence Measure at hospital discharge [73]. Nutritional intervention with rehabilitation may prevent the muscle atrophy because the skeletal mass index, measured using BIA, increased in the eight-week intervention of leucine-enriched amino acid supplementation and low-intensity resistance training [74].

In stroke survivors, fat mass increases due to muscle degeneration and BIA can be used to monitor fat mass [75]. BIA measurement of fat mass correlates with DEXA [76]. In an interventional study, progressive resistance and balance training reduced fat mass and improved walking capacity one year after stroke [77].

\section{Dual energy X-ray absorptiometry (DEXA)}

\subsection{Methodoligy}

DEXA uses two X-rays and measures the absorption in different tissues and indirectly measures the body composition. It is performed with the patient in the supine 
position in the examination room. Radiation exposure in DEXA is limited to one-tenth of that of a chest X-ray [78]. DEXA can measure lean body mass, which has a strong association with muscle mass measurement using CT [79].

\subsection{Applications in stroke}

The use of DEXA is reported in the subacute or chronic phase after stroke. In the subacute phase after stroke, muscle mass decreased by $6.1 \%$ and $1.8 \%$ in the affected and unaffected sides, respectively [80]. In a study, lean body mass decreased by $3 \%-4 \%$ over six months after stroke [81]. In another study, muscle atrophy remained in the affected side one year after stroke, but muscle mass was regained at the unaffected side [82]. One year after stroke, lower lean body mass was associated with impaired physical function, defined as Barthel Index of $<60$ points (OR, 137.9; 95\% CI, 2.04-9324.7; p = 0.02) [83]. Moreover, the decreased lean body mass was associated with decreased bone mineral density $\left(\mathrm{r}^{2}=0.371 ; \mathrm{p}<0.001\right)[84]$.

\section{Biomarkers}

Two biomarkers are used to assess muscle mass in patients with stroke. Urinary titin $\mathrm{N}$-fragment is an important biomarker in muscle atrophy [85]. Ishihara et al. have investigated the use of a urinary titin $\mathrm{N}$-fragment in stroke [53]. In their study, urinary titin $\mathrm{N}$-fragment increased within $2 \mathrm{~h}$ after the onset of stroke and they suggested that brainmuscle cross-talk occurs immediately after stroke. Moreover, the increased urinary titin $\mathrm{N}$-fragment was associated with the modified Rankin Scale score $(\mathrm{r}=0.55 ; \mathrm{p}<0.01)$, National Institutes of Health Stroke Scale score $(\mathrm{r}=0.72, \mathrm{p}<0.01)$, and Barthel Index $(\mathrm{r}=$ $-0.59 ; \mathrm{p}<0.01)$ at hospital discharge, and urinary titin $\mathrm{N}$-fragment on day 2 predicted the functional outcome at hospital discharge (OR, 1.11; 95\% CI, 1.01-1.28) in multivariate analysis after adjusting for the stroke severity. Alternatively, Scherbakov et al. have investigated the use of a C-terminal agrin fragment as a biomarker of muscle atrophy in stroke and found that the C-terminal agrin fragment increased in the subacute phase after acute stroke [86]. Moreover, the increased C-terminal agrin fragment was associated with increased lean body mass and improved handgrip strength of the affected arm. Further studies are required to find candidate biomarkers after stroke.

\section{Anthropometrics}

\subsection{Midupper arm circumference and triceps skinfold thickness}

Midupper arm circumference and triceps skinfold thickness have been used for decades to assess nutritional status after stroke (Figure 5) [87]. Arm muscle circumference is calculated from the following formula: midupper arm circumference $-(0.314 \times$ triceps skinfold thickness). Midupper arm circumference measurements are correlated with body mass index $(r=0.87)$ after stroke [88]. The midupper arm circumference measurement at the unaffected side has a superior diagnostic capacity for predicting malnutrition than triceps skinfold thickness and arm muscle circumference, and the area under the curve of midupper arm circumference, triceps skinfold thickness, and arm muscle circumference was $0.825,0.764$, and 0.745 , respectively, for men and $0.843,0.796$, and 0.742 , respectively, for women [89]. 
A

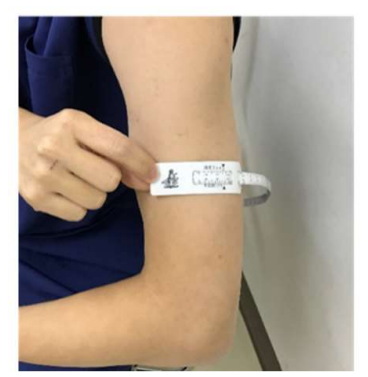

B

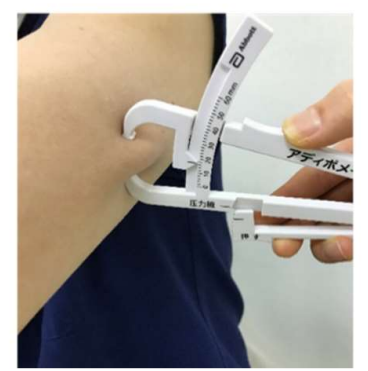

$\mathrm{C}$

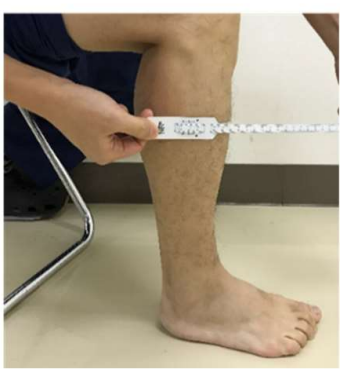

Figure 5. Anthropometrics. A. Mid-upper arm circumference. B. Triceps skinfold thickness. C. Calf circumference. Measurements were conducted using an insertape and adipometer (Abbott Japan, Tokyo, Japan).

\subsection{Calf circumference}

Calf circumference is a reliable indicator for assessing muscle mass because it is correlated with medial gastrocnemius muscle thickness measured using ultrasound $(\mathrm{r}=$ 0.432; $\mathrm{p}<0.001$ ) [90]. The calf circumference is measured at the maximum point with the patients seated or in the recumbent position at a $90^{\circ}$ angle of the knee. In stroke, the cutoff values were $33 \mathrm{~cm}$ for men (sensitivity 75\% and specificity 100\%) and $32 \mathrm{~cm}$ for women (sensitivity $80 \%$ and specificity $100 \%$ ) to assess sarcopenia [91]. In another study, the cutoff values were $34 \mathrm{~cm}$ for men (sensitivity $85 \%$ and specificity $66 \%$ ) and $33 \mathrm{~cm}$ for women (sensitivity $91 \%$ and specificity 28\%) [92]. After stroke, calf circumference was a more suitable method for assessing malnutrition than arm circumference, triceps skinfold thickness, and arm muscle circumference [89].

\section{Conclusions}

Muscle mass is important after stroke, and muscle atrophy occurs in the affected and unaffected limbs. Muscle mass measurement and monitoring can be conducted using CT, ultrasonography, BIA, DEXA, biomarkers, and anthropometrics. A clear understanding of these methods is important to properly use these methods for better rehabilitation and nutrition management in patients with stroke.

Author Contributions: Conceptualization, writing, and revision, N.N.; writing-computed tomography, K.T.; writing-ultrasound in limbs, K.N.; writing-ultrasound in diaphragm, K.O.; writing-bioelectrical impedance analysis, M.O.; writing-biomarker, A.S.; writinganthropometrics, S.K. All authors have read and agreed to the published version of the manuscript.

Funding: This work was supported by a crowdfunding project entitled the Muscle Atrophy Zero Project, using the platform "Otsucle" <https://otsucle.jp/cf/project/2553.html $>$. This work was partially supported by JSPS KAKENHI Grant Number JP20K17899.

Acknowledgments: The authors thank people who supported the Muscle Atrophy Zero Project, which aims to prevent muscle atrophy in critically ill patients. This work was partially supported by JSPS KAKENHI Grant Number JP20K17899.

Conflicts of Interest: The authors declare no conflict of interest.

\section{References.}

1. Donkor ES. Stroke in the 21(st) century: A snapshot of the burden, epidemiology, and quality of life. Stroke Res Treat 2018,2018,3238165, doi:10.1155/2018/3238165

2. Seminog OO, Scarborough P, Wright FL, Rayner M, Goldacre MJ. Determinants of the decline in mortality from acute stroke in England: Linked national database study of 795869 adults. Bmj 2019,365,11778, doi:10.1136/bmj.11778 
3. Yousef HA, Khalil HW, Nazzal MS, El-Salem KI, Hawamdeh ZM, Almeida P. Prevalence and predictors of return to work among stroke survivors in Jordan. Work 2020,67,817-827, doi:10.3233/wor-203334

4. Sions JM, Tyrell CM, Knarr BA, Jancosko A, Binder-Macleod SA. Age- and stroke-related skeletal muscle changes: a review for the geriatric clinician. J Geriatr Phys Ther 2012,35,155-161, doi:10.1519/JPT.0b013e318236db92

5. Abe T, Iwata K, Yoshimura Y, Shinoda T, Inagaki Y, Ohya S, Yamada K, Oyanagi K, Maekawa Y, Honda A, et al. Low muscle mass is associated with walking function in patients with acute ischemic stroke. J Stroke Cerebrovasc Dis 2020,29,105259, doi:10.1016/j.jstrokecerebrovasdis.2020.105259

6. Park JG, Lee KW, Kim SB, Lee JH, Kim YH. Effect of decreased skeletal muscle index and hand grip strength on functional recovery in subacute ambulatory stroke patients. Ann Rehabil Med 2019,43,535-543, doi:10.5535/arm.2019.43.5.535

7. Su Y, Yuki M, Otsuki M. Prevalence of stroke-related sarcopenia: A systematic review and meta-analysis. J Stroke Cerebrovasc Dis 2020,29,105092, doi:10.1016/j.jstrokecerebrovasdis.2020.105092

8. English C, McLennan H, Thoirs K, Coates A, Bernhardt J. Loss of skeletal muscle mass after stroke: A systematic review. International Journal of Stroke 2010,5,395-402, doi:10.1111/j.1747-4949.2010.00467.x

9. Mitsiopoulos N, Baumgartner RN, Heymsfield SB, Lyons W, Gallagher D, Ross R. Cadaver validation of skeletal muscle measurement by magnetic resonance imaging and computerized tomography. J Appl Physiol (1985) 1998,85,115-122, doi:10.1152/jappl.1998.85.1.115

10. van Vugt JL, Levolger S, Gharbharan A, Koek M, Niessen WJ, Burger JW, Willemsen SP, de Bruin RW, JN IJ. A comparative study of software programmes for cross-sectional skeletal muscle and adipose tissue measurements on abdominal computed tomography scans of rectal cancer patients. J Cachexia Sarcopenia Muscle 2017,8,285-297, doi:10.1002/jcsm.12158

11. Gomez-Perez SL, Haus JM, Sheean P, Patel B, Mar W, Chaudhry V, McKeever L, Braunschweig C. Measuring abdominal circumference and skeletal muscle from a single cross-sectional computed tomography image: A step-by-step guide for clinicians using national institutes of health imageJ. JPEN J Parenter Enteral Nutr 2016,40,308-318, doi:10.1177/0148607115604149

12. Mourtzakis M, Prado CM, Lieffers JR, Reiman T, McCargar LJ, Baracos VE. A practical and precise approach to quantification of body composition in cancer patients using computed tomography images acquired during routine care. Appl Physiol Nutr Metab 2008,33,997-1006, doi:10.1139/h08-075

13. Leitner J, Pelster S, Schöpf V, Berghoff AS, Woitek R, Asenbaum U, Nenning KH, Widhalm G, Kiesel B, Gatterbauer B, et al. High correlation of temporal muscle thickness with lumbar skeletal muscle cross-sectional area in patients with brain metastases. PLoS One 2018,13,e0207849, doi:10.1371/journal.pone.0207849

14. Nozoe M, Kubo H, Kanai M, Yamamoto M, Okakita M, Suzuki H, Shimada S, Mase K. Reliability and validity of measuring temporal muscle thickness as the evaluation of sarcopenia risk and the relationship with functional outcome in older patients with acute stroke. Clin Neurol Neurosurg 2021,201,106444, doi:10.1016/j.clineuro.2020.106444

15. Steindl A, Leitner J, Schwarz M, Nenning KH, Asenbaum U, Mayer S, Woitek R, Weber M, Schöpf V, Berghoff AS, et al. Sarcopenia in neurological patients: Standard values for temporal muscle thickness and muscle strength evaluation. J Clin Med 2020,9, doi:10.3390/jcm9051272

16. Katsuki M, Suzuki Y, Kunitoki K, Sato Y, Sasaki K, Mashiyama S, Matsuoka R, Allen E, Saimaru H, Sugawara $\mathrm{R}$, et al. Temporal muscle as an indicator of sarcopenia is independently associated with Hunt and Kosnik grade on admission and the Modified Rankin Scale score at 6 months of patients with subarachnoid hemorrhage treated by endovascular coiling. World Neurosurg 2020,137,e526-e534, doi:10.1016/j.wneu.2020.02.033 
17. Katsuki M, Yamamoto Y, Uchiyama T, Wada N, Kakizawa Y. Clinical characteristics of aneurysmal subarachnoid hemorrhage in the elderly over 75; Would temporal muscle be a potential prognostic factor as an indicator of sarcopenia? Clin Neurol Neurosurg 2019,186,105535, doi:10.1016/j.clineuro.2019.105535

18. Ranganathan K, Terjimanian M, Lisiecki J, Rinkinen J, Mukkamala A, Brownley C, Buchman SR, Wang SC, Levi B. Temporalis muscle morphomics: the psoas of the craniofacial skeleton. J Surg Res 2014,186,246-252, doi:10.1016/j.jss.2013.07.059

19. Swartz JE, Pothen AJ, Wegner I, Smid EJ, Swart KM, de Bree R, Leenen LP, Grolman W. Feasibility of using head and neck CT imaging to assess skeletal muscle mass in head and neck cancer patients. Oral Oncol 2016,62,28-33, doi:10.1016/j.oraloncology.2016.09.006

20. Aubrey J, Esfandiari N, Baracos VE, Buteau FA, Frenette J, Putman CT, Mazurak VC. Measurement of skeletal muscle radiation attenuation and basis of its biological variation. Acta Physiol (Oxf) 2014,210,489-497, doi:10.1111/apha.12224

21. Lee Y, Ko R, Ahn J, Cariere K, Ryu J. Prognostic value of muscle mass measured via brain computed tomography in neurocritically ill patients. Preprint 2020, doi:10.21203/rs.3.rs-125437/v1

22. Tsuji T, Liu M, Hase K, Masakado Y, Chino N. Trunk muscles in persons with hemiparetic stroke evaluated with computed tomography. J Rehabil Med 2003,35,184-188, doi:10.1080/16501970306126

23. Cho $\mathrm{KH}$, Lee HJ, Lee WH. Intra- and inter-rater reliabilities of measurement of ultrasound imaging for muscle thickness and pennation angle of tibialis anterior muscle in stroke patients. Top Stroke Rehabil 2017,24,368-373, doi:10.1080/10749357.2017.1285745

24. Berenpas F, Martens AM, Weerdesteyn V, Geurts AC, van Alfen N. Bilateral changes in muscle architecture of physically active people with chronic stroke: A quantitative muscle ultrasound study. Clin Neurophysiol 2017,128,115-122, doi:10.1016/j.clinph.2016.10.096

25. Calvo-Lobo C, Useros-Olmo AI, Almazán-Polo J, Becerro-de-Bengoa-Vallejo R, Losa-Iglesias ME, PalomoLópez P, Rodríguez-Sanz D, López-López D. Rehabilitative ultrasound imaging of the bilateral intrinsic plantar muscles and fascia in post-stroke survivors with hemiparesis: A case-control study. Int J Med Sci 2018,15,907914, doi:10.7150/ijms.25836

26. Triandafilou KM, Kamper DG. Investigation of hand muscle atrophy in stroke survivors. Clin Biomech (Bristol, Avon) 2012,27,268-272, doi:10.1016/j.clinbiomech.2011.10.002

27. Nakanishi N, Tsutsumi R, Okayama Y, Takashima T, Ueno Y, Itagaki T, Tsutsumi Y, Sakaue H, Oto J. Monitoring of muscle mass in critically ill patients: comparison of ultrasound and two bioelectrical impedance analysis devices. J Intensive Care 2019,7,61, doi:10.1186/s40560-019-0416-y

28. Nozoe M, Kanai M, Kubo H, Yamamoto M, Shimada S, Mase K. Non-paretic lower limb muscle wasting during acute phase is associated with dependent ambulation in patients with stroke. J Clin Neurosci 2020,74,141-145, doi:10.1016/j.jocn.2020.02.020

29. Hacker ED, Peters T, Garkova M. Ultrasound assessment of the rectus femoris cross-sectional area: Subject position implications. West J Nurs Res 2016,38,1221-1230, doi:10.1177/0193945916644751

30. e Lima KM, da Matta TT, de Oliveira LF. Reliability of the rectus femoris muscle cross-sectional area measurements by ultrasonography. Clin Physiol Funct Imaging 2012,32,221-226, doi:10.1111/j.1475097X.2011.01115.x

31. Pardo E, El Behi H, Boizeau P, Verdonk F, Alberti C, Lescot T. Reliability of ultrasound measurements of quadriceps muscle thickness in critically ill patients. BMC Anesthesiology 2018,18,205, doi:10.1186/s12871-0180647-9 
32. Mandal S, Suh E, Thompson A, Connolly B, Ramsay M, Harding R, Puthucheary Z, Moxham J, Hart N. Comparative study of linear and curvilinear ultrasound probes to assess quadriceps rectus femoris muscle mass in healthy subjects and in patients with chronic respiratory disease. BMJ Open Respir Res 2016,3,e000103, doi:10.1136/bmjresp-2015-000103

33. Takahashi Y, Saito A, Sato H, Shibata K, Okura K, Kinoshita K, Seto A, Osawa S, Wakasa M, Kimoto M, et al. In vivo flattening of the central aponeurosis of the rectus femoris due to knee extension torque in healthy young and elderly individuals with knee osteoarthritis. Ultrasound Q 2019, doi:10.1097/ruq.0000000000000443

34. Harris-Love MO, Monfaredi R, Ismail C, Blackman MR, Cleary K. Quantitative ultrasound: measurement considerations for the assessment of muscular dystrophy and sarcopenia. Frontiers in Aging Neuroscience 2014,6, doi:10.3389/fnagi.2014.00172

35. Whittaker JL, Warner MB, Stokes MJ. Induced transducer orientation during ultrasound imaging: effects on abdominal muscle thickness and bladder position. Ultrasound Med Biol 2009,35,1803-1811, doi:10.1016/j.ultrasmedbio.2009.05.018

36. Puthucheary ZA, McNelly AS, Rawal J, Connolly B, Sidhu PS, Rowlerson A, Moxham J, Harridge SD, Hart N, Montgomery HE. Rectus femoris cross-sectional area and muscle layer thickness: comparative markers of muscle wasting and weakness. Am J Respir Crit Care Med 2017,195,136-138, doi:10.1164/rccm.201604-0875LE

37. Palakshappa JA, Reilly JP, Schweickert WD, Anderson BJ, Khoury V, Shashaty MG, Fitzgerald D, Forker C, Butler K, Ittner CA, et al. Quantitative peripheral muscle ultrasound in sepsis: muscle area superior to thickness. J Crit Care 2018,47,324-330, doi:10.1016/j.jcrc.2018.04.003

38. English CK, Thoirs KA, Fisher L, McLennan H, Bernhardt J. Ultrasound is a reliable measure of muscle thickness in acute stroke patients, for some, but not all anatomical sites: A study of the intra-rater reliability of muscle thickness measures in acute stroke patients. Ultrasound in Medicine $\mathcal{E}$ Biology 2012,38,368-376, doi:https://doi.org/10.1016/j.ultrasmedbio.2011.12.012

39. Nakanishi N, Oto J, Tsutsumi R, Iuchi M, Onodera M, Nishimura M. Upper and lower limb muscle atrophy in critically ill patients: An observational ultrasonography study. Intensive Care Med 2018,44,263-264, doi:10.1007/s00134-017-4975-x

40. Pillen S, Tak RO, Zwarts MJ, Lammens MM, Verrijp KN, Arts IM, van der Laak JA, Hoogerbrugge PM, van Engelen BG, Verrips A. Skeletal muscle ultrasound: correlation between fibrous tissue and echo intensity. Ultrasound Med Biol 2009,35,443-446, doi:10.1016/j.ultrasmedbio.2008.09.016

41. Parry SM, El-Ansary D, Cartwright MS, Sarwal A, Berney S, Koopman R, Annoni R, Puthucheary Z, Gordon IR, Morris PE, et al. Ultrasonography in the intensive care setting can be used to detect changes in the quality and quantity of muscle and is related to muscle strength and function. J Crit Care 2015,30,1151.e1159-1114, doi:10.1016/j.jcrc.2015.05.024

42. Monjo H, Fukumoto Y, Asai T, Shuntoh H. Muscle thickness and echo intensity of the abdominal and lower extremity muscles in stroke survivors. J Clin Neurol 2018,14,549-554, doi:10.3988/jcn.2018.14.4.549

43. Nozoe M, Kanai M, Kubo H, Kobayashi M, Yamamoto M, Shimada S, Mase K. Quadriceps muscle thickness changes in patients with aneurysmal subarachnoid hemorrhage during the acute phase. Top Stroke Rehabil 2018,25,209-213, doi:10.1080/10749357.2017.1413762

44. Akazawa N, Harada K, Okawa N, Kishi M, Tamura K, Moriyama H. Changes in quadriceps thickness and echo intensity in chronic stroke survivors: A 3-year longitudinal study. J Stroke Cerebrovasc Dis 2020,30,105543, doi:10.1016/j.jstrokecerebrovasdis.2020.105543

45. Lee SS, Spear S, Rymer WZ. Quantifying changes in material properties of stroke-impaired muscle. Clin Biomech (Bristol, Avon) 2015,30,269-275, doi:10.1016/j.clinbiomech.2015.01.004 
46. Narici MV, Roi GS, Landoni L, Minetti AE, Cerretelli P. Changes in force, cross-sectional area and neural activation during strength training and detraining of the human quadriceps. European Journal of Applied Physiology and Occupational Physiology 1989,59,310-319, doi:10.1007/BF02388334

47. Okamoto S, Sonoda S, Tanino G, Tomida K, Okazaki H, Kondo I. Change in thigh muscle cross-sectional area through administration of an anabolic steroid during routine stroke rehabilitation in hemiplegic patients. Am $J$ Phys Med Rehabil 2011,90,106-111, doi:10.1097/PHM.0b013e31820172bf

48. Wait JL, Nahormek PA, Yost WT, Rochester DP. Diaphragmatic thickness-lung volume relationship in vivo. J Appl Physiol (1985) 1989,67,1560-1568, doi:10.1152/jappl.1989.67.4.1560

49. Goligher EC, Laghi F, Detsky ME, Farias P, Murray A, Brace D, Brochard LJ, Bolz SS, Rubenfeld GD, Kavanagh $\mathrm{BP}$, et al. Measuring diaphragm thickness with ultrasound in mechanically ventilated patients: feasibility, reproducibility and validity. Intensive Care Med 2015,41,734, doi:10.1007/s00134-015-3724-2

50. Carrillo-Esper R, Pérez-Calatayud Á A, Arch-Tirado E, Díaz-Carrillo MA, Garrido-Aguirre E, Tapia-Velazco R, Peña-Pérez CA, Espinoza-de Los Monteros I, Meza-Márquez JM, Flores-Rivera OI, et al. Standardization of sonographic diaphragm thickness evaluations in healthy volunteers. Respir Care 2016,61,920-924, doi:10.4187/respcare.03999

51. Zambon M, Greco M, Bocchino S, Cabrini L, Beccaria PF, Zangrillo A. Assessment of diaphragmatic dysfunction in the critically ill patient with ultrasound: A systematic review. Intensive Care Med 2017,43,29-38, doi:10.1007/s00134-016-4524-z

52. Goligher EC, Dres M, Fan E, Rubenfeld GD, Scales DC, Herridge MS, Vorona S, Sklar MC, Rittayamai N, Lanys A, et al. Mechanical ventilation-induced diaphragm atrophy strongly impacts clinical outcomes. Am J Respir Crit Care Med 2018,197,204-213, doi:10.1164/rccm.201703-0536OC

53. Umbrello M, Formenti P, Longhi D, Galimberti A, Piva I, Pezzi A, Mistraletti G, Marini JJ, Iapichino G. Diaphragm ultrasound as indicator of respiratory effort in critically ill patients undergoing assisted mechanical ventilation: A pilot clinical study. Crit Care 2015,19,161, doi:10.1186/s13054-015-0894-9

54. Catalá-Ripoll JV, Monsalve-Naharro J, Hernández-Fernández F. Incidence and predictive factors of diaphragmatic dysfunction in acute stroke. BMC Neurol 2020,20,79, doi:10.1186/s12883-020-01664-w

55. Kim M, Lee K, Cho J, Lee W. Diaphragm thickness and inspiratory muscle functions in chronic stroke patients. Med Sci Monit 2017,23,1247-1253, doi:10.12659/msm.900529

56. Cohen E, Mier A, Heywood P, Murphy K, Boultbee J, Guz A. Diaphragmatic movement in hemiplegic patients measured by ultrasonography. Thorax 1994,49,890-895, doi:10.1136/thx.49.9.890

57. Similowski T, Catala M, Rancurel G, Derenne JP. Impairment of central motor conduction to the diaphragm in stroke. Am J Respir Crit Care Med 1996,154,436-441, doi:10.1164/ajrccm.154.2.8756819

58. Choi YM, Park GY, Yoo Y, Sohn D, Jang Y, Im S. Reduced diaphragm excursion during reflexive citric acid cough test in subjects with subacute stroke. Respir Care 2017,62,1571-1581, doi:10.4187/respcare.05488

59. Pozuelo-Carrascosa DP, Carmona-Torres JM, Laredo-Aguilera JA, Latorre-Román P, Párraga-Montilla JA, Cobo-Cuenca AI. Effectiveness of respiratory muscle training for pulmonary function and walking ability in patients with stroke: A systematic review with meta-analysis. Int J Environ Res Public Health 2020,17, doi:10.3390/ijerph17155356

60. Kim D, Sun JS, Lee YH, Lee JH, Hong J, Lee JM. Comparative assessment of skeletal muscle mass using computerized tomography and bioelectrical impedance analysis in critically ill patients. Clin Nutr 2018, doi:10.1016/j.clnu.2018.12.002

61. Kushner RF, Gudivaka R, Schoeller DA. Clinical characteristics influencing bioelectrical impedance analysis measurements. Am J Clin Nutr 1996,64,423s-427s, doi:10.1093/ajcn/64.3.423S 
62. Przysada G, Czenczek-Lewandowska E, Wyszyńska J, Weres A, Baran J, Kwolek A, Leszczak J. Effect of poststroke rehabilitation on body mass composition in relation to socio-demographic and clinical factors. Int $J$ Environ Res Public Health 2020,17, doi:10.3390/ijerph17145134

63. Vahlberg B, Zetterberg L, Lindmark B, Hellström K, Cederholm T. Functional performance, nutritional status, and body composition in ambulant community-dwelling individuals 1-3 years after suffering from a cerebral infarction or intracerebral bleeding. BMC Geriatr 2016,16,48, doi:10.1186/s12877-016-0226-1

64. Ishiguro N, Kanehisa H, Miyatani M, Masuo Y, Fukunaga T. A comparison of three bioelectrical impedance analyses for predicting lean body mass in a population with a large difference in muscularity. European Journal of Applied Physiology 2005,94,25-35, doi:10.1007/s00421-004-1259-2

65. Kim SJ, Yu EH, Min JH, Shin YI, Ko HY, Ko SH. Segmental Bioelectrical Impedance Analysis of the Body Composition of Affected and Unaffected Limbs After Hemiparetic Stroke. Am J Phys Med Rehabil 2020,99,830836, doi:10.1097/phm.0000000000001434

66. Guedes DP, Calabrese JC, Pirolli PM. Use of different segmental multi-frequency bioelectrical impedance devices for analysis of body composition in young adults: comparison with bioelectrical spectroscopy. Nutr Hosp 2019,36,618-625, doi:10.20960/nh.2376

67. Chen LK, Woo J, Assantachai P, Auyeung TW, Chou MY, Iijima K, Jang HC, Kang L, Kim M, Kim S, et al. Asian working group for sarcopenia: 2019 Consensus update on sarcopenia diagnosis and treatment. J Am Med Dir Assoc 2020,21,300-307.e302, doi:10.1016/j.jamda.2019.12.012

68. Ohyama K, Watanabe M, Nosaki Y, Hara T, Iwai K, Mokuno K. Correlation between skeletal muscle mass deficit and poor functional outcome in patients with acute ischemic stroke. J Stroke Cerebrovasc Dis 2020,29,104623, doi:10.1016/j.jstrokecerebrovasdis.2019.104623

69. Irisawa H, Mizushima T. Correlation of body composition and nutritional status with functional recovery in stroke rehabilitation patients. Nutrients 2020,12, doi:10.3390/nu12071923

70. Celik B, Ones K, Ince N. Body composition after stroke. Int J Rehabil Res 2008,31,93-96, doi:10.1097/MRR.0b013e3282f7521a

71. Shiraishi A, Yoshimura Y, Wakabayashi H, Tsuji Y. Prevalence of stroke-related sarcopenia and its association with poor oral status in post-acute stroke patients: Implications for oral sarcopenia. Clin Nutr 2018,37,204-207, doi:10.1016/j.clnu.2016.12.002

72. Matsushita T, Nishioka S, Taguchi S, Yamanouchi A, Nakashima R, Wakabayashi H. Sarcopenic obesity and activities of daily living in stroke rehabilitation patients: A cross-sectional study. Healthcare (Basel) 2020,8, doi:10.3390/healthcare8030255

73. Nagano F, Yoshimura Y, Bise T, Shimazu S, Shiraishi A. Muscle mass gain is positively associated with functional recovery in patients with sarcopenia after stroke. J Stroke Cerebrovasc Dis 2020,29,105017, doi:10.1016/j.jstrokecerebrovasdis.2020.105017

74. Yoshimura Y, Bise T, Shimazu S, Tanoue M, Tomioka Y, Araki M, Nishino T, Kuzuhara A, Takatsuki F. Effects of a leucine-enriched amino acid supplement on muscle mass, muscle strength, and physical function in poststroke patients with sarcopenia: A randomized controlled trial. Nutrition 2019,58,1-6, doi:10.1016/j.nut.2018.05.028

75. English C, Thoirs K, Coates A, Ryan A, Bernhardt J. Changes in fat mass in stroke survivors: a systematic review. Int J Stroke 2012,7,491-498, doi:10.1111/j.1747-4949.2012.00824.x

76. Kafri MW, Potter JF, Myint PK. Multi-frequency bioelectrical impedance analysis for assessing fat mass and fatfree mass in stroke or transient ischaemic attack patients. Eur J Clin Nutr 2014,68,677-682, doi:10.1038/ejcn.2013.266 
77. Vahlberg B, Lindmark B, Zetterberg L, Hellström K, Cederholm T. Body composition and physical function after progressive resistance and balance training among older adults after stroke: an exploratory randomized controlled trial. Disabil Rehabil 2017,39,1207-1214, doi:10.1080/09638288.2016.1191551

78. Lewis MK, Blake GM, Fogelman I. Patient dose in dual x-ray absorptiometry. Osteoporos Int 1994,4,11-15, doi:10.1007/bf02352255

79. Hansen RD, Williamson DA, Finnegan TP, Lloyd BD, Grady JN, Diamond TH, Smith EU, Stavrinos TM, Thompson MW, Gwinn TH, et al. Estimation of thigh muscle cross-sectional area by dual-energy X-ray absorptiometry in frail elderly patients. Am J Clin Nutr 2007,86,952-958, doi:10.1093/ajcn/86.4.952

80. Tamura A, Ichihara T, Takata S, Minagawa T, Kuwamura Y, Bando T, Kondo H, Yasui N, Nagahiro S. Changes in lower extremity muscle mass among bedridden patients with post-stroke hemiplegia in the acute post-stroke period. JNI 2006,5,18-21,

81. Ryan AS, Dobrovolny CL, Smith GV, Silver KH, Macko RF. Hemiparetic muscle atrophy and increased intramuscular fat in stroke patients. Arch Phys Med Rehabil 2002,83,1703-1707, doi:10.1053/apmr.2002.36399

82. Jørgensen L, Jacobsen BK. Changes in muscle mass, fat mass, and bone mineral content in the legs after stroke: A 1 year prospective study. Bone 2001,28,655-659, doi:10.1016/s8756-3282(01)00434-3

83. Scherbakov N, Pietrock C, Sandek A, Ebner N, Valentova M, Springer J, Schefold JC, von Haehling S, Anker SD, Norman K, et al. Body weight changes and incidence of cachexia after stroke. J Cachexia Sarcopenia Muscle 2019,10,611-620, doi:10.1002/jcsm.12400

84. Pang MY, Eng JJ, McKay HA, Dawson AS. Reduced hip bone mineral density is related to physical fitness and leg lean mass in ambulatory individuals with chronic stroke. Osteoporos Int 2005,16,1769-1779, doi:10.1007/s00198-005-1925-1

85. Nakanishi N, Tsutsumi R, Hara K, Takashima T, Nakataki E, Itagaki T, Matsuo M, Oto J, Sakaue H. Urinary titin is a novel biomarker for muscle atrophy in nonsurgical critically ill patients: A two-center, prospective observational study. Crit Care Med 2020,48,1327-1333, doi:10.1097/CCM.0000000000004486

86. Scherbakov N, Knops M, Ebner N, Valentova M, Sandek A, Grittner U, Dahinden P, Hettwer S, Schefold JC, von Haehling S, et al. Evaluation of C-terminal Agrin Fragment as a marker of muscle wasting in patients after acute stroke during early rehabilitation. J Cachexia Sarcopenia Muscle 2016,7,60-67, doi:10.1002/jcsm.12068

87. Foley NC, Salter KL, Robertson J, Teasell RW, Woodbury MG. Which reported estimate of the prevalence of malnutrition after stroke is valid? Stroke 2009,40,e66-74, doi:10.1161/strokeaha.108.518910

88. Ha L, Hauge T, Iversen PO. Body composition in older acute stroke patients after treatment with individualized, nutritional supplementation while in hospital. BMC Geriatrics 2010,10,75, doi:10.1186/1471-2318-10-75

89. Nishioka S, Wakabayashi H, Yoshida T. Accuracy of non-paralytic anthropometric data for nutritional screening in older patients with stroke and hemiplegia. Eur $J$ Clin Nutr 2017,71,173-179, doi:10.1038/ejcn.2016.191

90. Macedo Fraiz G, Herminia Gallo L, Iraci Rabito E, Silveira Gomes AR, Madalozzo Schieferdecker ME. Relationship between muscle thickness and calf circumference in healthy older women. Arch Gerontol Geriatr 2020,86,103942, doi:10.1016/j.archger.2019.103942

91. Nishioka S, Yamanouchi A, Matsushita T, Nishioka E, Mori N, Taguchi S. Validity of calf circumference for estimating skeletal muscle mass for Asian patients after stroke. Nutrition 2020,111028, doi:10.1016/j.nut.2020.111028

92. Inoue T, Maeda K, Shimizu A, Nagano A, Ueshima J, Sato K, Murotani K. Calf circumference value for sarcopenia screening among older adults with stroke. Arch Gerontol Geriatr 2020,93,104290, doi:10.1016/j.archger.2020.104290 
